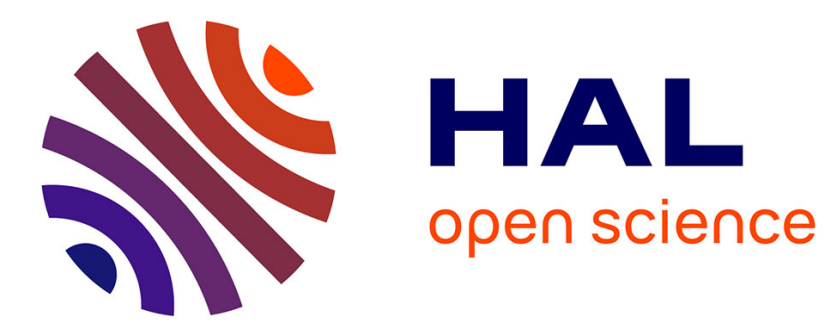

\title{
Improvement of the simulation tools dedicated to composite structures subjected to crash loads
}

Patrick Rozycki, Daniel Coutellier

\section{To cite this version:}

Patrick Rozycki, Daniel Coutellier. Improvement of the simulation tools dedicated to composite structures subjected to crash loads. IDMME 2002 - 4th International Conference on Integrated Desisn and Manufacturing in Mechanical Engineering, 2003, Clermont-ferrand, France. 10.1007/978-94-0170161-7_11. hal-01008299

\section{HAL Id: hal-01008299 \\ https://hal.science/hal-01008299}

Submitted on 13 Jul 2021

HAL is a multi-disciplinary open access archive for the deposit and dissemination of scientific research documents, whether they are published or not. The documents may come from teaching and research institutions in France or abroad, or from public or private research centers.
L'archive ouverte pluridisciplinaire HAL, est destinée au dépôt et à la diffusion de documents scientifiques de niveau recherche, publiés ou non, émanant des établissements d'enseignement et de recherche français ou étrangers, des laboratoires publics ou privés. 


\title{
IMPROVEMENT OF THE SIMULATION TOOLS DEDICATED TO COMPOSITE STRUCTURES SUBJECTED TO CRASH LOADS
}

\author{
P. Rozycki and D. Coutellier \\ LAMIH, University of Valenciennes and Hainaut-Cambrésis, France
}

\begin{abstract}
In the framework of transport industries, vehicle design optimisation represents a key priority issue. Indeed, this is a result of the huge pressures imposed on industrialists particularly in terms of active safety. Moreover, among of all the materials used for design, some such as composite materials require special attention. It is consequently within this framework that we propose to describe in this paper the contributions which were made to the numerical simulation tools for structural analysis. The latter can involve crash type loading for example. In a first instance, certain behavioural phenomena and their integration into the computational code will be described. Secondly, some elementary validations will be presented. Finally, some applications relating to the dimensioning of panels in composites subjected to linear or point impacts will be revealed. The conclusions of these studies will enable us to show, on the one hand, a certain reliability of the developments which permit their use as design tools but also, on the other hand, to foresee the prospects of future research.
\end{abstract}

Key words: Composite materials, numerical simulations, design, crash

\section{INTRODUCTION}

Structural design optimisation in the transport industries highlights an increasingly high use of data-processing tools. Indeed, computation software allows industrialists to meet the requirements induced both by the economic and ecological contexts, such as cutting manufacturing costs and time. Nowadays, they are completely integrated within the various certification, standardisation or safety processes whose drastic criteria impose a constant increase in the structure's reliability and viability. 
From this point of view, our research team has developed, in close relations with industrialists, a new finite element within an explicit code. Its main specificity is to come up to the dimensioning of multi-layered multimaterial structures subjected to crash loads [1] [2] [3] [4]. These materials are a combination of metal and fibre/resin composite layers and they are devoted to the design of certain aircraft fuselages.

However, the purely composite laminated materials make significantly great strides, essentially due to their mechanical characteristic properties: by including them into some structural parts, it is possible to obtain responses for extreme requests. Consequently, it appears necessary to optimise the means suggested by the computer codes so that these new tools facilitate the design of these new structures for the industrialists.

The aim of this article is to present the improvements brought about to the previous finite element with regard to fibre/resin composite plies. Therefore, some general background information on the finite element is initially presented. An experimental quantisation of strain rate sensitivity for unidirectional composite materials is then tackled. This part continues by a theoretical approach adapted to the description of viscous phenomena. Finally, some simple and complex validation cases are presented which allow to conclude on the future prospects generated by this study.

\section{THE MULTI-LAYERED MULTI-MATERIAL FINITE ELEMENT}

\subsection{Generality}

The multi-layered multi-material element [5] is a three or four nodes finite shell element. It is based on the Mindlin-Reissner theory. The attached assumptions mainly impose a state of plane stresses and an invariance of the deformation through the thickness. In addition to both assumptions, it is assumed that the transverse and shear effects are taken into account. The interpolation functions relating to the finite element are bilinear.

Owing to the ply concept, the stacking and the nature of materials composing the structure to be designed (multi-layered multi-material, laminated composites, etc) are reproduced. The constituent materials can be only of the metallic, composite or foam type. Each ply has its own material characteristics, its own behaviour laws as well as a point of integration through thickness, located in the middle section of the ply. 


\subsection{Unidirectional composite elementary ply modelling}

The finite element offers the choice between two possibilities for the modelling of the unidirectional composite elementary ply. The first model is known as "bi-phase" [6] [7] [8] and distinguishes the fibre behaviour from the matrix one. The second model is known as "global" and a homogenized behavioural law describes the behaviour of an elementary ply [9] [10]. The optimisation is based on the latter model: the essential reason lies in the fact that this model features an easy experimental methodology in order to identify material characteristics. It is thus an essential asset for the software users.

The global model allows the transcription of considerable phenomena such as elasticity, plasticity and certain types of degradation. The latter correspond to the micro-cracking of the matrix parallel to fibres, the debonding of fibre/resin and finally the rupture of fibres. The plastic flow is taken into account using a standard "von Mises" plasticity criterion coupled to an isotropic hardening law. Owing to the effective stress concept, the damage is integrated into the plastic flow. All the material parameters corresponding to this elastic plastic damaging law are identified thanks to some simple or cyclic tensile and compressive tests on five laminates with preset orientations [11].

\subsection{Positioning of the problem}

In order to justify the validity of the finite element introduced for the multi-layered multi-material structure dimensioning, some results are shown here. They are related to dynamic three point bending on plates composed of aluminium and composite glass-E/epoxy layers [1] [12] [13] We can note a very good correlation between the experimental results and the values resulting from the numerical simulation with the new multimaterial element (figure 1). For each case, the maximum error featured is lower than $12 \%$. As one could expect, the superposition of elements with different behaviours does not agree at all with the treatment of the structures subjected to bending loads. Our development thus introduces new possibilities for the numerical simulation study of multi-material laminated structures. Other applications on tubes impacted in axial compression have also produced numerical results in agreement with the experimentation [2] [3] [4] [12] [13]. The tubes were formed of one steel layer reinforced by rolling up glass fibres and epoxy resin. They can be connected to energy absorbers. 


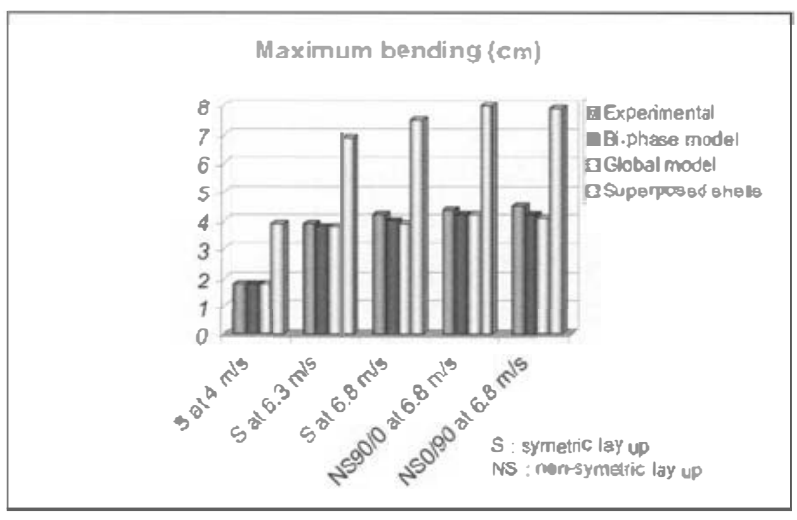

Figure - I. Maximum bending to dimension GLARE plates.

The results previously cited have confirmed the validity of the finite elcment within the integration of a multi-layered multi-material study framework. Howcver, the applications often relate to accidental shocks (automotive crash, bird impact on a wing section, meteorite impact on a protection shield, etc) during which an influencing parameter can intervene: the strain rate.

\section{STRAIN RATE SENSITIVITY OF UNIDIRECTIONAL COMPOSITE MATERIALS}

For conventional materials such as metallic ones, behaviour laws suitably include the influence of the strain rate parameter. However, for laminated composites, the complexity of their intrinsic behaviour means that the static study of these materials must be supplemented by a dynamic one in order to check, and in the optimal case to quantify, the sensitivity of the material parameters to the load velocity.

\subsection{Some experimental observations}

The experimental campaign has concerned strain rate sensitivity of the material parameters of elastic plastic damaging law. Indeed, it is then possible to maintain certain reproducibility as well as feasibility for the computational code users with regard to characterisation tests. Moreover, it is also possible to preserve the global model underlying. The tests taken into account are consequently composed of tensile tests on laminates $[0]_{4}$, $[ \pm 45]_{S},[ \pm 67.5]_{S},[+45]_{4}$ and of a compressive test on laminate $[\mathbf{0}]_{6}$. 
The experimental device consists of a dynamic tension/compression machine (rapid hydraulic jack). For each type of test, four main load velocities were applied: $5 \mathrm{~mm} / \mathrm{min}, 500 \mathrm{~mm} / \mathrm{min}, 0.2 \mathrm{~m} / \mathrm{s}$ and $4 \mathrm{~m} / \mathrm{s}$. Some intermediate velocities were introduced, thus increasing the results' accuracy. The strain rate covered ranges from quasi-static state to approximately $150 \mathrm{~s}^{-1}$.

Two essential conclusions arise from the experimental tests: first, as figures 2 and 3 show, elastic moduli, initial yield stress and longitudinal fracture stress undergo a significant increase starting from a certain threshold strain rate. These increases are about $30 \%$ to $300 \%$ according to the constants. Then, we note that in the longitudinal case (figure 2), there is a behaviour law conservation since the aforementioned remains fragile and elastic. However, in the shearing case (figure 3), the type of behaviour tends to become "damaging elastic" under strain rate influence.

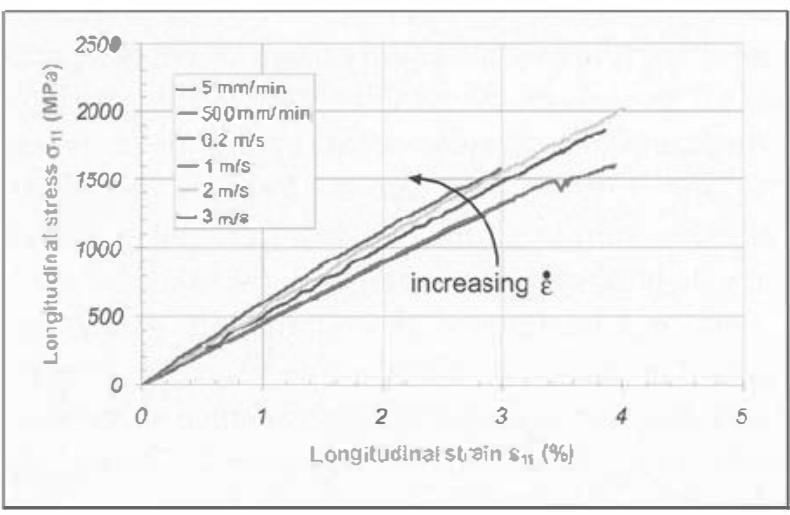

Figure -2. Dynamic tensilc tests on laminate []$_{4}$

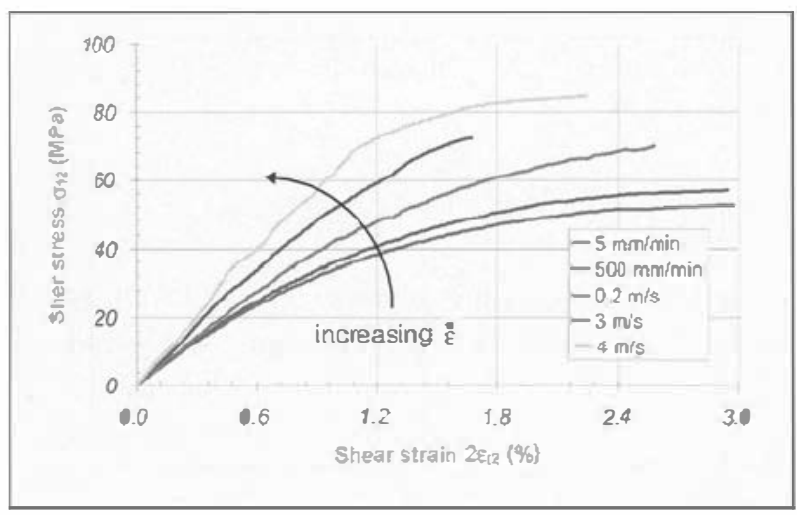

Figure -3 . Dynamic tensile tests on laminate $[ \pm 45]_{s}$. 
Consequently, the assumption adopted is that behaviour law can be described overall as a "viscous" elastic plastic damaging law and, at a given strain rate, can be always identified, starting from a behaviour "reference" law. Lastly, the evolution of all previous constants are, for this glassE/epoxy composite, in an analytical form power according to the strain rate [14].

\subsection{Theoretical approach: "viscous" modelling}

The type of behaviour observed in experiments is not easily identifiable: it represents neither visco-elasticity nor visco-plasticity. However, it is possible to approach the definition suggested by Lemaitre and Chaboche [15] with regard to viscous fluids.

Indeed, epoxy resins, and more generally reticulate polymers, are sensitive to the strain rate during loads [16]: viscosity primarily comes from the chain segment movements through barriers of energy potentials. These phenomena are all the more active (since they are thermally activated) as the vitreous transition temperature from epoxy resin is relatively low (between $50^{\circ} \mathrm{C}$ and $150^{\circ} \mathrm{C}$ ). We can be led to think that this rise in temperature, as a function of strain rate, brings about some micro-changes in resin phases, which thus tend to become "soft" solids.

However, it should be noticed that strain rate influence on material behaviour is certainly related to the resin dependence with respect to this strain rate, but is also closely related to the choice of components. Some studies on carbon/epoxy unidirectional laminates [17] have shown a strain rate insensitivity of the elastic moduli: carbon fibres have a Young modulus on average three times higher than that of glass-E fibres and thus inhibit the viscous effects of resin (in the elastic range).

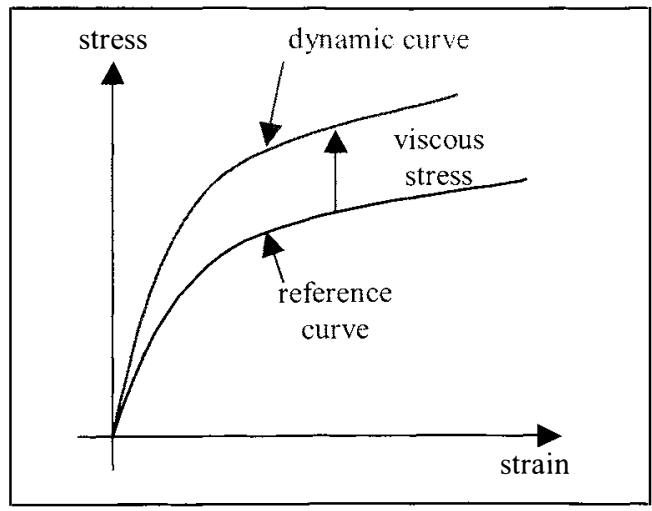

Figure -4. Definition of viscous stress. 
Modelling results from the approach of viscous fluids [14]: the "pseudovisco-elasticity" of resin (and in fact of laminated composite) are taken into account using a viscous stress, which is itself combined with the elastic stress (figure 4). Indeed, in experiments, it is always possible to determine the behaviour at a given strain rate according to behaviour at a reference strain rate.

In order to integrate the pseudo-visco-elastic nature of resin, the idea is to consider that dissipation's potential form is identical to the thermodynamic potential one, with the help of some characteristic functions of resin viscosity. Therefore, the stress tensor becomes as equation (1) according to the state law and the complementary law.

$$
\underline{\underline{\sigma}}=C^{0}: \underline{\underline{\varepsilon}}^{e}+\Theta: \underline{\underline{\varepsilon}}^{e} \quad(\Theta: \text { viscous tensor })
$$

The development of equation (1) for longitudinal, transverse and shear direction results in a description of elastic range. However, it is simplified owing to the approximation due to the dynamic rapid load type we are faced with. It can then be attributed to this general equation describing the elastic range:

$$
\underset{\underline{\sigma}}{=} C^{0}(I+F)::_{\underline{\varepsilon}}^{e} \quad(F: \text { viscous functions })
$$

In a phenomenological way, the material state (resin or composite) can always be given starting from its state in the reference configuration. We can thus suppose that the state for a given strain rate corresponds to the quasi-static state of another glass E/epoxy composite material from which material characteristics are different. Since the elastic moduli can increasingly evolve with the strain rate, this assumption results in postulating a damage progress faster than that of the reference case. It is possible to show that the constant damage evolution intrinsic to modelling [14], is a function root of the viscosity shear function:

$$
\begin{aligned}
& Y_{i j}(\dot{\varepsilon}) \approx \sqrt{\left(1+F_{12}(\dot{\varepsilon})\right)} Y_{i j} \\
& \text { where } Y_{i j} \text { represent each damage parameter }
\end{aligned}
$$

The previous assumption also suggests that the plasticity field moves accordingly (with an evolution of initial yield stress). Indeed, the initial yield stress undergoes an evolution of the same type as the elasticity moduli (4). Resin plasticity is coupled with the model by supposing that the plastic 
strain evolution is similar to the reference case. However, they are delayed since the material becomes increasingly "rigid".

$$
R_{0}(\dot{\varepsilon})=\left(1+F_{R}(\dot{\varepsilon})\right) R_{0}
$$

Finally, we put forward the additional assumption that the energy rate required to break the laminate (in the transverse and/ør shear directions) is insensitive to the strain rate.

\section{VALIDATIONS OF THE IMPLEMENTATION}

\subsection{Elementary numerical validations}

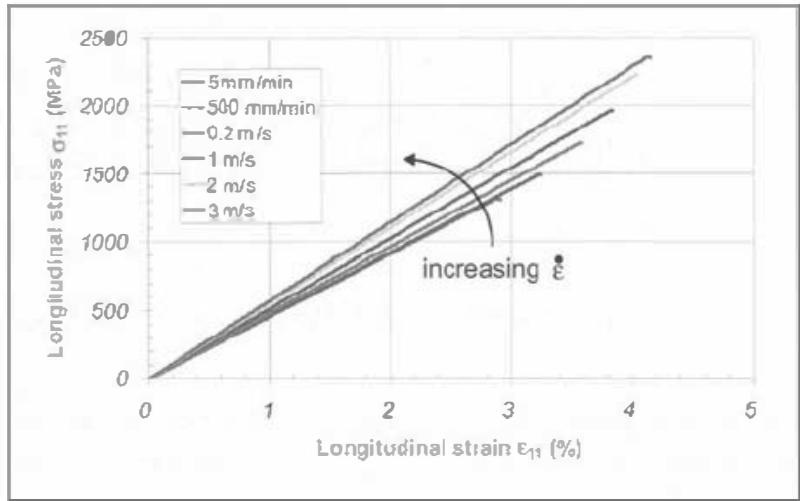

Figzure -5. Numerical dynamic tensile tests on laminate $[0]_{4}$.

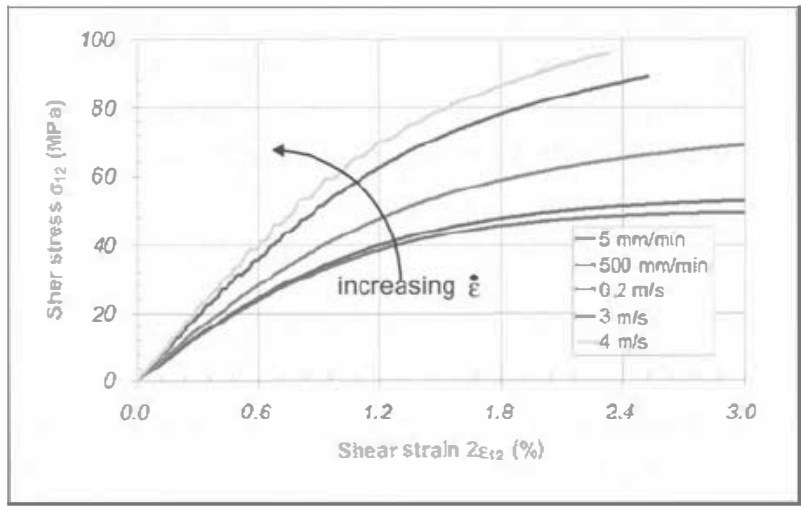

Figure - Numerical dynamic tensile tests on laminate $[ \pm 45]_{S}$. 
Initially, it is necessary to check that the "primary" theoretical behaviours are suitably represented: therefore, we have carried out validations known as elementary [14]. They correspond to the simulation of experimental tensile or compressive tests derived from the static or dynamic study framework. In each case, the test piece is represented - since its geometry makes it possible - by a single shell element. Figures 5 and 6 as compared to figures 2 and 3 visually show that the approach developed seems to correlate satisfactorily with the experiment.

\subsection{Application to the case of plates subjected to impacts}

Since the "viscous" behaviour law seems to be validated satisfactorily for the identification tests, we have started an experimental campaign in connection with more complex loads such as three point dynamic bending

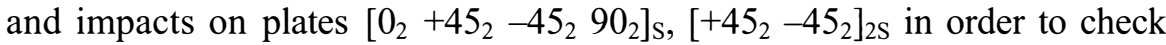
the reliability of the developments. In this part, we have some preliminary results [18] derived from the examinations of an impacted plate $\left[0_{2}+45_{2}-\right.$ $\left.\begin{array}{ll}45_{2} & 90_{2}\end{array}\right]_{\mathrm{s}}$. A spherical ball, coupled to a carriage, proposes a mass of 26.5 $\mathrm{kg}$ and a velocity of $4 \mathrm{~m} / \mathrm{s}$ at impact moment.

In figure 7, we compare the experimental and numerical evolutions of applied load versus time. The first observations tend to show that the strain rate sensitivity integration is a significant precaution since it allows to correct the structure rigidity adequately: the average strain rate observed at impact point is indeed about $100 \mathrm{~s}^{-1}$ (figure 8). The temporal description of load seems to use the behavioural law optimisation more satisfactorily than that proposed by "quasi-static" modelling. Indeed, the first maximum load observed supported by the plate is around $1.5 \mathrm{~ms}$.

However, figure 7 highlights that the maximum load rate, applied to the plate always remains lower than the experimental one although a temporal description is satisfactory. Indeed, during tests we have observed the appearance of delamination between certain plies (hatched surface on figure 7). However the numerical modelling adopted does not take into account this phenomenon; we suppose that this difference in load rate results from a brutal "numerical" degradation of the structure rather than a gradual degradation observed in experiments. The state of damage is distributed in a prompt and integral way depending on the thickness of the laminate whereas in experiments the appearance of delamination authorizes the conservation of a certain structure integrity and thus of its rigidity. Studies are currently in progress in order to apply a methodology developed within the laboratory [19] to validate this assumption. 


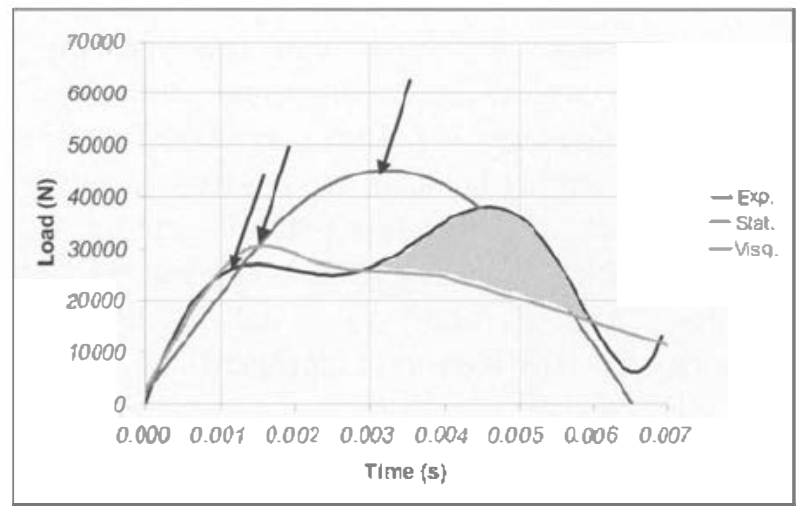

Figure -7. Experimental and numcrical comparisons for an impact.

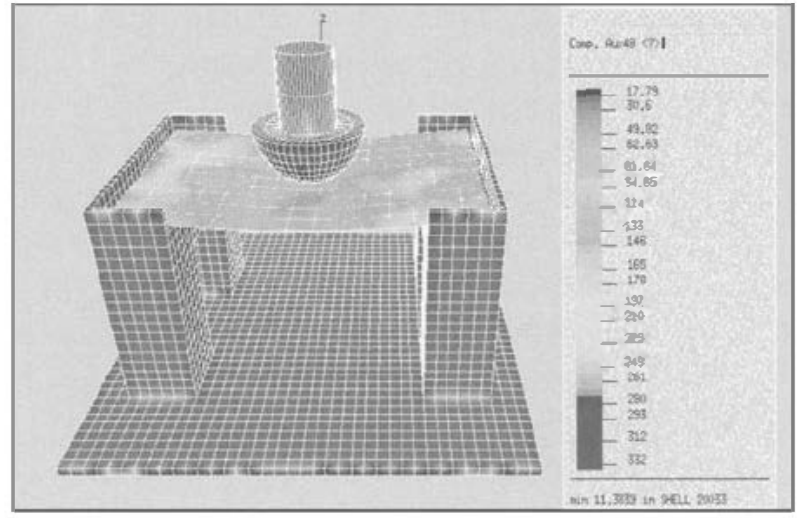

Figure -8. Numcrical contour of the strain rate.

\section{CONCLUSIONS AND FUTURE PROSPECTS}

The few results presented enable us to highlight a certain relevance of the original approach adopted. Indeed, the elementary or complex validations show that the theoretical and data-processing developments lead to being taken into account the strain rate influence satisfactorily. The optimisation of the data-processing tools allows the computational code users to possess a powerful tool. They can simulate structure dimensioning including not only multi-layered multi-material but also laminated fibre/resin composites.

The whole approach was transposed with the same conclusions as previously, to fabric glass E/epoxy or carbon/epoxy laminates. These results consequently encourage us to continue and refine our work, in particular by 
proposing a more suitable description integrating the temperature rise phenomena. Other studies are also in progress in order to integrate the major delamination phenomena.

\section{ACKNOWLEDGMENTS}

We thank Mr. E Haug and Mr. X Ni from ESI Software Company as well as the ANRT, which have allowed the realisation of this thesis subject under a CIFRE agreement. We address also our warmest thanks to ONERA of Lille, and more particularly to Mr. E Deltombe and Mr. D. Dormegnie, for their support and for the realisation of the whole experimental tests. Finally, we thank the CNRS for their permanent support of the laboratory.

\section{REFERENCES}

[1] D. COUTEllier, C. GAUThIER, Y. RAVAlaRD, X. NI, E. HAUG, "Modélisation en flexion des multicouches et multi-matériaux en dynamique rapide", JNC 10, D. Baptiste \& A. Vautrin, 1996, pp. 969-980.

[2] D. COUTEllier, C. GAUTHIER, P. ROZYCKI, Y. RAVALARD, "Numerical simulation of the tensile behaviour of multi-layered multi-material within an explicit software code", European Journal of Mechanical Environmental Engineering, vol 43, 1998, pp.51-60.

[3] C. GAUTHIER, D. COUTEllier, Y. RAVAlaRD, "Modélisation d'un élément multicouches et multi-matériaux dans le logiciel d'éléments finis PAMCRASH"M", Giens95, 1995, pp. 373-378.

[4] C. GAUTHIER, "Contribution à la modélisation du comportement en crash des structures stratifiées métal/composite. Développement d'un élément de coque multi-couches multimatériaux", thèse de l'Université de Valenciennes et du Hainaut-Cambrésis, 1996.

[5] Pam Crash" ${ }^{\mathrm{TM}}$, "Solver Notes Manual \& Solver Reference Manual”, ESI Group Software product company, Rungis, 1998.

[6] E. HAUG, H. CHARLIER, J. CLINCKEMAILLE, "Recent trends and developments of crashworthiness simulation methodologies and their integration into industrial vehicle design cycle", Third European Cars/Trucks Simulation Symposium (ASIMUTH), 1991.

[7] E. HAUG, A. DE ROUVRAY, "Crash response of composite structure", Chapter 7 of Structural Crashworthiness and Failure, Ed. by N. Jones \& T. Wierrzbicki, Elsevier, London, 1993.

[8] A.K. PICKETT, J. RUCKERT, E. HAUG, "A fracture damaging law suitable for anisotropic short fibre/matrix materials in an explicit finite element code", Journal of Composites, Vol. 21, n4, 1990, pp 297-304.

[9] P. LADEVEZE, "Sur la mécanique de l'endommagement des composites”, JNC 5, Ed. Pluralis, Paris, 1986, pp. 667-683

[10] O. ALLIX, P. LADEVEZE, E. LE DANTEC, "Modélisation de l'endommagement du pli élémentaire des composites stratifiés", JNC 7, Ed. Pluralis, Lyon, 1990, pp. 715-724. 
[11] D. COUTELLIER, P. ROZYCKI, "New functionalities for PAMCRASH"M multilayered multi-material element", Composites Part A - Applied Science and Manufacturing, 2000, Vol-31, pp. 841-851.

[12] P. ROZYCKI, "Flexion trois points dynamique sur des plaques de multicouches multimatériaux", Mémoire de D.E.A., Partie ${ }^{\circ} 1$, Université de Valenciennes et du HainautCambrésis, 1996.

[13] P. ROZYCKI, "Compression dynamique de multicouches multi-matériaux", Mémoire de D.E.A., Partie n², Université de Valenciennes et du Hainaut-Cambrésis, 1996.

[14] P. ROZYCKI, "Contribution au développement de lois de comportement pour matériaux composites soumis à l'impact", thèse de l'Université de Valenciennes et du Hainaut-Cambrésis. Valenciennes, 2000.

[15] J. LEMAITRE, J.L. CHABOCHE, "Mécanique des matériaux solides", Ed Dunos, Paris, 1985, Chapitre $1:$ pp. 26-31, chapitre $4:$ pp. 145-148.

[16] J.L. CHABOCHE, "Formalisme général des lois de comportements: applications aux métaux et polymères. Introduction à la mécanique des polymères", Ed. G'sell C. \& Haudin J.M., Nancy, 1995, pp. 119-140.

[17] O. ALLIX, J.F. DEU, P. LADEVEZE, “A delay-damage meso-model for the prediction of localisation and fracture of laminates subjected to high-rate loading", ECCM'99, European Conference on Computational Mechanics, München, Germany, 1999.

[18] P. ROZYCKI, "Validations numériques de la loi élasto-plastique endommageable visqueuse - Essais de flexion trois points dynamiques et impact de plaques", rapport interne de l'Université de Valenciennes, 2001, à paraître.

[19] J.C. WALRICK, "Contribution au développement d'une nouvelle méthodologie pour l'étude du délaminage dans les structures stratifiées composites : application à l'impact basse vitesse", thèse de l'Université de Valenciennes et du Hainaut-Cambrésis, Valenciennes, 1999. 